Journal of Applied Pharmaceutical Science Vol. 6 (06), pp. 061-065, June, 2016

Available online at http://www.japsonline.com

DOI: 10.7324/JAPS.2016.60611

ISSN 2231-3354 (cc) BY-NC-SA

\title{
In vitro Anticoagulant Activity of Siddha Sastric Formulation Linga Mathirai compared with Low Molecular Weight Heparin
}

\author{
Thanigavelan Vembu ${ }^{1 *}$, Mathukumar Sivagnanam², Pitchiah Kumar Murugan ${ }^{3}$ \\ ${ }^{1}$ Part time Research Scholar, Department of Siddha, The Tamil Nadu Dr. MGR Medical University and Associate Professor, Sairam Advanced Centre for \\ Research, Sri Sairam Siddha Medical College, Chennai, Tamil Nadu, India. ${ }^{2}$ Professor cum Principal, Sri Sairam Siddha Medical College and Research \\ Centre, Chennai, Tamil Nadu, India. ${ }^{3}$ State Drug Licensing Authority (Indian Medicine), Post graduate department of Gunapadam, Government Siddha \\ Medical College, Chennai, Tamil Nadu, India.
}

\begin{tabular}{|c|c|}
\hline ARTICLE INFO & ABSTRACT \\
\hline Article history: & \multirow{9}{*}{$\begin{array}{l}\text { Linga Mathirai (LM) is a Siddha Sastric formulation indicated for treating cardiovascular diseases. The present } \\
\text { study aimed to evaluate the efficacy of LM against the formation of thrombus and platelet aggregation on } \\
\text { compared with Low molecular weight Heparin. In vitro clot lysis and platelet aggregation assays were employed } \\
\text { for the study on blood samples of rat. Whole blood samples and platelets obtained by centrifugation were used } \\
\text { for clot lysis and aggregation assay respectively. Platelet aggregation was induced by agonists Thrombin and } \\
\text { Adenosine diphosphate (ADP). The different concentrations of LM }(100,200,500,1000 \mu \mathrm{L} \text { ) were prepared } \\
\text { with the adjuvant Ginger decoction for test samples and } 100 \mu \mathrm{L} \text { low molecular weight heparin (LMWH) was } \\
\text { used for treating standard group. Against clot formation and platelet aggregation, LM did not exhibit significant } \\
\text { efficacy on compared with normal saline (control) and heparin. However, LM at its higher concentration } 1000 \\
\mu \mathrm{L} \text { exhibited significant inhibitory activity on platelet aggregation induced by both Thrombin and ADP when } \\
\text { compared with distilled water (control). Under this study, it is concluded that the test drug Linga Mathirai had } \\
\text { comparable and slightly lesser efficacy than low molecular weight heparin. }\end{array}$} \\
\hline Received on: $09 / 04 / 2016$ & \\
\hline Revised on: $15 / 05 / 2016$ & \\
\hline Accepted on: 01/06/2016 & \\
\hline Available online: $28 / 06 / 2016$ & \\
\hline & \\
\hline Siddha, Mathirai, Lingam, & \\
\hline & \\
\hline aggregation, Anticoagulant. & \\
\hline
\end{tabular}

\section{INTRODUCTION}

The formation of thrombus at the site of atherosclerotic plaque is a major cause for Myocardial Infarction, Unstable Angina and Stroke in the setting of Coronary and Cerebral artery diseases (Badimon et al., 2012). Fibrin, thrombin and platelets forms main component in thrombus (Vermylen et al., 1986). Currently available thrombolytic drugs have the ability to dissolve the blood clot but contraindicated in patients who have undergone surgery and patients having history of bleeding disorders, bleeding condition in gastro intestinal tract and hypertension etc. Thrombolytic drugs could not have the potency against platelet aggregation. For therapeutic administration,

\footnotetext{
* Corresponding Author

Thanigavelan Vembu, Associate Professor, Department of Gunapadam, Sairam Advanced Centre for Research, Sri Sairam Siddha Medical College and Research Centre, Chennai, India.

Email:thaniga.velan@gmail.com
}

thrombolytic drugs are augmented with antiplatelet drugs (Umesh et al., 2014). These issues directed the interest of research towards the compounds derived from plants and natural sources having anticoagulant and antiplatelet activity. Certain studies have reported that bioactive compounds isolated from Gingko biloba, Bacopa monnieri Linn, Lagenaria siceraria and Ananas comosus inhibit the platelet aggregation and thrombin activity (Henry et al., 2009; Kojima et al., 1986; Matsuura, 2001; Pietri et al., 1997). Till now, there is a lacuna in the field of research on natural minerals in medicines. All the matters existing in the universe including human body is made up of five primordial elements viz., Vinn (Space), Vali (Air), Thee (Fire), Neer (Water) and Mann (Earth) according to Pancha bootham theory in Siddha system of Medicine. These five elements form the basis of body constitution, characteristics, tastes, diseases and their treatment. The body has seven basic physical constituents called Udal Thathukkal viz., Saaram, Senneer, Oon, Kozhuppu, Enbu, Moolai and Sukkilam/Suronitham. 
Each physical constituent is related with a part of the body. Saaram and Senneer are related with plasma and blood respectively which are made up of basic elements - water and fire (Jayaprakash et al., 2011).

According to the fundamentals of Siddha, Lingam a mercurial compound having fire element can be used in treating the diseases of blood vessels since it has the property in curing the diseases which affects the water element in the body (Thiyagarajan, 2008). Lingam based formulations has been used in the treatment of Vatha diseases, chronic inflammatory diseases such as arthritis, dermatitis, etc and hemiplegia. Linga Mathirai (LM) is a Siddha Sastric pill comprises of purified Lingam done by Surukku method (Cinnabar - Mercuric Sulphide) and purified Vengaaram (Borax) done by frying method mixed in equal proportions and triturated with breast milk. In the literature, $60 \mathrm{mg}$ of LM is indicated for the management of Uruthira Vaiyvu along with the adjuvant Ginger juice or Ginger decoction (Abdhula, 1995). Uruthira Vaiyvu or Thamaraga Noi is a Siddha terminology for cardiovascular disease having cardinal features of shortness of breath, chest pain, weakness, fatigue and pedal oedema (Kuppusamy, 2004).

The present study was designed as a preliminary screening for the evaluation of anticoagulant and antiplatelet activity of Linga Mathirai and done by two assays such as clot lysis and platelet aggregation.

\section{MATERIALS AND METHODS}

\section{Preparation of test sample}

A sufficient quantity of Linga Mathirai was ground into fine powder in a mortar and stored in air tight sterile container. In humans, the mode of administration of LM is mentioned as two times daily, per oral suspended in $10 \mathrm{~mL}$ of Ginger decoction as adjuvant at $60 \mathrm{mg}$ dosage. Ginger decoction was prepared by the following procedure. The dried rhizome of Ginger $10 \mathrm{~g}$ was coarsely powdered and taken in a $500 \mathrm{~mL}$ glass jar. To this $200 \mathrm{~mL}$ of water was added and heated mounting over the hot plate boiling down to $50 \mathrm{~mL}$ and filtered to get Ginger decoction. For each study, freshly prepared test sample was prepared by suspending powdered LM $60 \mathrm{mg}$ in the adjuvant Ginger decoction $10 \mathrm{~mL}$ (6 mg LM in $1 \mathrm{~mL}$ decoction).

\section{Animal procurement and maintenance}

Sprague dawley rats of weighing $150 \mathrm{~g}$ to $200 \mathrm{~g}$ were purchased from Sri Venkateshwara Enterprises, Bengaluru, India and they were acclimatized in Animal house of Sairam Advanced Centre for Research Chennai, India at $21-23^{\circ} \mathrm{C}$ after getting IAEC approval. Animal ethical guidelines of CPCSEA, Ministry of Animal Husbandry and Welfare, Govt. of India were strictly followed for the care and maintenance of procured animals. The animals were fed on standard rodent pellet and RO water was provided ad libitum. The animals were kept at overnight fasting before experimentation.

\section{In vitro clot lysis activity}

The study was performed by the basis of clot dissolution method (Prasad et al., 2006).

\section{Materials}

Micro pipettes $100 \mu \mathrm{L}, 200 \mu \mathrm{L}, 500 \mu \mathrm{L}, 1000 \mu \mathrm{L}$, Eppendorf tubes $1.5 \mathrm{ml}$, Heparin - LMWX (Enoxaparin Sodium) $40 \mathrm{mg}$ in $0.4 \mathrm{~mL}$ (Gland Pharma Ltd, Hyderabad), Normal Saline, LM test sample and $3 \mathrm{~mL}$ blood each from four Sprague dawley rats $(\mathrm{A}, \mathrm{B}, \mathrm{C} \& \mathrm{D})$.

\section{Procedure}

Four healthy Sprague dawley rats were randomly selected and allotted as A, B, C \& D. Six sterile Eppendorf tubes were weighed, noted (W1) and numbered as A1, A2, A3, A4, A5 and A6. $3 \mathrm{~mL}$ of fresh blood was withdrawn from the Sprague dawley rat ' $A$ ' through cardiac puncture immediately after sacrificed under $\mathrm{CO}_{2}$ inhalation. $500 \mu \mathrm{L}$ blood samples were added to A1-A6 tubes and incubated at $37^{\circ} \mathrm{C}$ for $45 \mathrm{~min}$. After $45 \mathrm{~min}$, clot was formed and the serum was aspirated out without disturbing the clot. The tubes with clot were weighed again and noted as W2. Then the clot weight (W3) before treatment was determined by $\mathrm{W} 2-\mathrm{W} 1$. Each tube with clot was treated as follows: A1 treated with $100 \mu \mathrm{L}$ of Normal Saline (Control), A2 treated with $100 \mu \mathrm{L}$ of Heparin (Standard) and A3 - A6 treated with $100 \mu \mathrm{L}, 200 \mu \mathrm{L}, 500 \mu \mathrm{L}$ and $1000 \mu \mathrm{L}$ test samples respectively. All the treated tubes were incubated for $90 \mathrm{~min}$ at $37^{\circ} \mathrm{C}$. After $90 \mathrm{~min}$, clot lysis was observed and the supernatant was aspirated from the tubes without disturbing the clot and immediately weighed as W4 (Weight of the tube with clot after treatment).

The weight of the clot after treatment (W5) was calculated by $\mathrm{W} 4-\mathrm{W} 1$ and percentage of clot lysis was determined by [(W3 - W5) / W3 x 100]. The same above procedure was carried out on the blood samples of B, C \& D. The weight of the clot was observed in four blood samples before and after treatment of control, standard and different concentrations of test samples. The percentages of clot lysis were observed.

\section{Platelet aggregation assay}

The inhibitory activity of test sample LM at different concentrations was tested separately on Thrombin and Adenosine diphosphate (ADP) induced platelet aggregation (Born and Cross, 1963).

\section{Materials}

3.8\% Sodium citrate, Adenosine diphosphate (ADP) - 5 $\mathrm{mM}$, Thrombin $5 \mathrm{U} / \mathrm{mL}$, Micro pipettes $100 \mu \mathrm{L}, 200 \mu \mathrm{L}, 500 \mu \mathrm{L}$, $1000 \mu \mathrm{L}$, Centrifuge tubes, Heparin - LMWX (Enoxaparin Sodium) $40 \mathrm{mg}$ in $0.4 \mathrm{~mL}$ (Gland Pharma Ltd, Hyderabad), Washing buffer (pH: $6.5 \& 7.4)$, LM test sample and $4.5 \mathrm{~mL}$ blood each from four Sprague dawley rats (A, B, C \& D). 


\section{Procedure}

A healthy Sprague dawley rat (A) was sacrificed under $\mathrm{CO} 2$ inhalation and immediately, $4.5 \mathrm{~mL}$ of blood was collected through cardiac puncture and transferred into a centrifuge tube containing $3.8 \%$ sodium citrate $(9: 1 \mathrm{v} / \mathrm{v})$. The blood was centrifuged at $1200 \mathrm{rpm}$ for $15 \mathrm{~min}$ and $2200 \mathrm{rpm}$ for $3 \mathrm{~min}$ consecutively. The supernatant was collected and centrifuged at $3200 \mathrm{rpm}$ for $15 \mathrm{~min}$. The supernatant was discarded and $5 \mathrm{~mL}$ of washing buffer ( $\mathrm{pH}$ : 6.5) was added to the sediment. The suspended sediment was centrifuged at $3000 \mathrm{rpm}$ for $15 \mathrm{~min}$ and supernatant was discarded. The platelets were collected as sediment and again suspended in $0.5 \mathrm{ml}$ of washing buffer $(\mathrm{pH}$ : 7.4) and stored in deep freezer at $-80^{\circ} \mathrm{C}$. The stored platelets were used within $4 \mathrm{~h}$ for the study. The distilled water $100 \mu \mathrm{L}$ (Control), Heparin $100 \mu \mathrm{L}$ (Standard) and test samples LM at 100, $200,500,1000 \mu \mathrm{L}$ were added to each $100 \mu \mathrm{L}$ platelets (A1, A2, $\mathrm{A} 3, \mathrm{~A} 4, \mathrm{~A} 5 \mathrm{\&} \mathrm{A} 6$ ) and incubated at $37^{\circ} \mathrm{C}$ for $5 \mathrm{~min}$. With these, Thrombin/ADP $20 \mu \mathrm{L}$ was added and again incubated at $37^{\circ} \mathrm{C}$ for $5 \mathrm{~min}$. The inhibition of platelet aggregation was measured at 412 $\mathrm{nm}$ using micro plate reader for $20 \mathrm{~min}$ at interval of $30 \mathrm{~s}$. The above same procedure was repeated on the platelets obtained from other three rats $(\mathrm{B}, \mathrm{C} \& \mathrm{D})$. The percentage of formation of Platelet aggregation induced by Thrombin and ADP and inhibition of Platelet aggregation in four blood samples were observed.

\section{Statistical analysis}

All data were expressed as Mean \pm Standard Error of Mean (SEM). All groups were compared among them for testing significance by one way ANOVA followed by Tukey Kramer Multiple Comparison test using GRAPH PAD INSTAT version 3 software programmes. Values of $\mathrm{p}<0.05$ were considered significant.

\section{RESULTS AND DISCUSSION}

Arteriosclerosis is the thickening, hardening and loss of elasticity of the walls of arteries. It is the major pathological cause for Coronary and Cerebral thrombosis leading to heart attack and stroke causing mortality and morbidity (Ernest and Virgina, 2010). Current researches recommend focusing on the development of thrombolytic drugs from natural sources and traditional system of medicines since undesirable adverse effects are caused by available thrombolytic drugs. For this present study, a Siddha Sastric formulation Linga Mathirai (LM) had been chosen considering as an effective drug for the treatment of inflammation related to blood vessels as cited in the literature.

Clot lysis activity of Linga Mathirai at different concentrations was done on blood samples of Sprague dawley rat and compared with the activity of Normal Saline as control and low molecular weight Heparin - Enoxaparin as standard. Enoxaparin is an anticoagulant drug which acts by inhibiting thrombin indirectly by binding to a protease inhibitor antithrombin III. Also, it inhibits platelet aggregation therefore serving as an effective control drug for in vitro studies (Janet, 2006). Enoxaparin has fibrinolytic activity through the stimulation of endothelial release of tissue plasminogen activator (t-PA) and inhibits coagulation activity by increasing the release of tissue factor pathway inhibitors (TFPI) (Wiegand et al., 2014). After incubation of $500 \mu \mathrm{L}$ of blood samples at $37^{\circ} \mathrm{C}$ for $45 \mathrm{~min}$, clot weight was noted and recorded as clot weight prior to the treatment of test samples. On treating with test samples, again the blood samples were incubated at $37^{\circ} \mathrm{C}$ for $90 \mathrm{~min}$ and clot weight was recorded as after treatment estimation. The blood samples treated with $100 \mu \mathrm{L}$ Normal saline had shown reduction in mean clot weight to $0.23 \mathrm{~g}$ from $0.27 \mathrm{~g}$ the difference been $0.04 \mathrm{~g}$. The blood samples treated with $100 \mu \mathrm{L}$ Heparin had shown in reduction of mean clot weight to $0.19 \mathrm{~g}$ from $0.26 \mathrm{~g}$ and the difference was $0.07 \mathrm{~g}$. The blood samples treated with $100 \mu \mathrm{L} \mathrm{LM}$ had shown in reduction of mean clot weight to $0.24 \mathrm{~g}$ from $0.29 \mathrm{~g}$ with the difference as $0.05 \mathrm{~g}$. The blood samples treated with $200 \mu \mathrm{L}$ LM had shown reduction in mean clot weight to $0.22 \mathrm{~g}$ from $0.27 \mathrm{~g}$, the difference calculated as $0.05 \mathrm{~g}$. The blood samples treated with $500 \mu \mathrm{L} \mathrm{LM}$ had shown reduction in mean clot weight to $0.24 \mathrm{~g}$ from $0.29 \mathrm{~g}$ and the difference was $0.05 \mathrm{~g}$. The blood samples treated with $1000 \mu \mathrm{L}$ $\mathrm{LM}$ had shown reduction of mean clot weight to $0.19 \mathrm{~g}$ from 0.25 $\mathrm{g}$ and the difference was $0.06 \mathrm{~g}$. The mean percentage of clot lysis for normal saline and heparin was found $14.72 \%$ and $24.69 \%$ respectively. But the mean percentage of clot lytic activity of 1000 $\mu \mathrm{L} \mathrm{LM}$ was found $24.12 \%$ and was not statistically significant when compared with control and standard. From the above results, we inferred that $100 \mu \mathrm{L}$ Heparin and $1000 \mu \mathrm{L} \mathrm{LM}$ both had clot lysis activity better than other group but no statistical significance in difference was observed in between the six groups and it is represented in the figure $1 \& 2$.

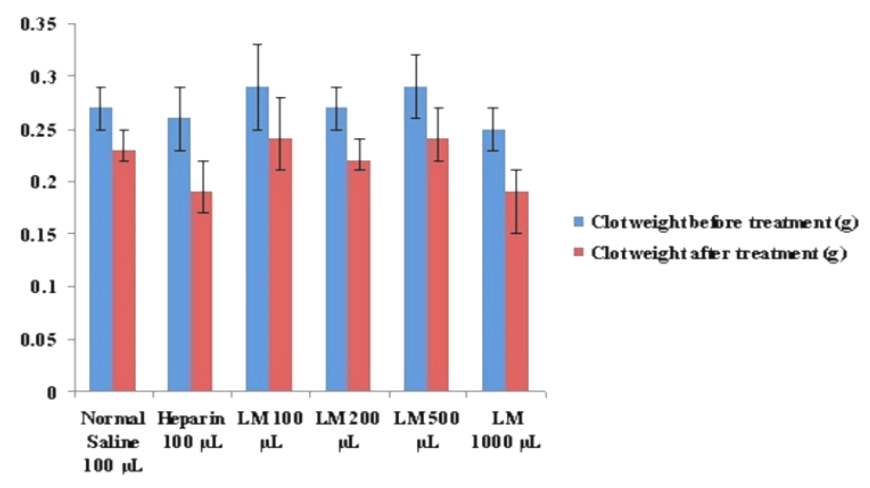

Fig. 1: Effect of the different concentrations of Linga Mathirai (LM) on the clot weight of rat blood samples compared to normal saline and low molecular weight heparin. Data are expressed as mean \pm SEM, where $n=4$. No significant differences are observed.

In many studies, Streptokinase has been used for treatment in the standard group and distilled water for treatment in normal group to determine the clot lysis activity of experimental drug. LMWH does not have much interference in inhibiting thrombin and fibrin formation on compared with other thrombolytic agents A study reported that on concomitant administration of heparin at its therapeutic dose with other thrombolytic agent - Tissue- type plasminogen activator (t-PA), 
heparin did not inhibit thrombolysis as compared with only t-PA treated blood samples (Fry and Sobel, 1988). But another study reported that LMWH on subcutaneous administration, it is effective and safety on usage as adjunct to rt-PA thrombolytic treatment for acute infarction (Chamuleau SA et al., 1998). From the present study, we inferred that normal saline has also some extent of inhibition against thrombin and fibrin formation. Hence in the further studies of platelet aggregation assay, distilled water was used for the treatment in normal group.

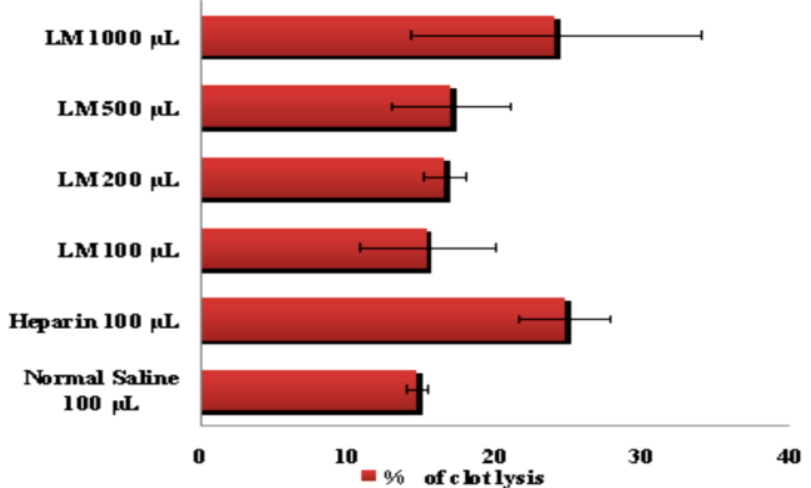

Fig. 2: Effect of the different concentrations of Linga Mathirai (LM) on percentage of clot lysis of rat blood samples compared to normal saline and low molecular weight heparin. Data are expressed as mean \pm SEM, where $n=4$. No significant differences are observed.

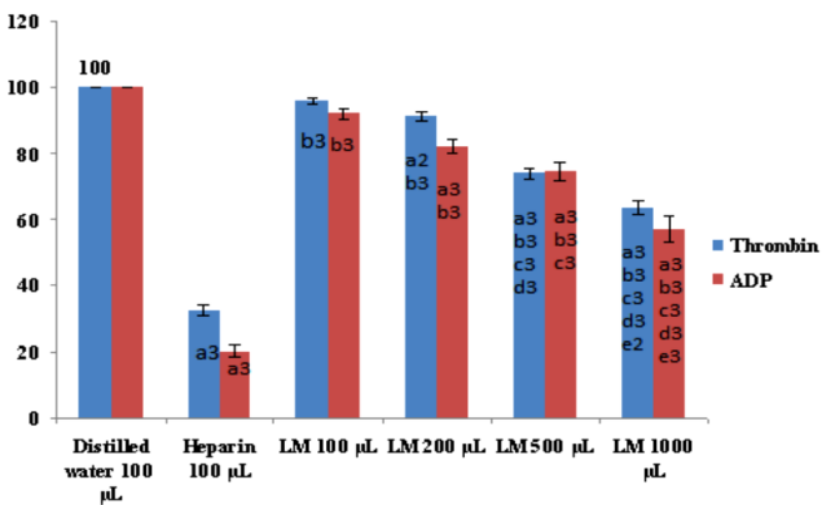

Fig. 3: Effect of the different concentrations of Linga Mathirai (LM) on percentage of aggregation formed on rat platelets induced by Thrombin and Adenosine diphosphate (ADP) compared to normal saline and low molecular weight heparin. Data are expressed as mean \pm SEM, where $n=4$; One way ANOVA: Tukey's multiple comparision test. ${ }^{\mathrm{a} 3} \mathrm{p}<0.001$ significantly different compared with platelets treated with distilled water. ${ }^{\mathrm{a} 2} \mathrm{p}<0.01$ significantly different compared with platelets treated with distilled water. ${ }^{\mathrm{b} 3} \mathrm{p}<0.001$ significantly different compared with platelets treated with heparin. ${ }^{\mathrm{c} 3} \mathrm{p}<0.001$ significantly different compared with platelets treated with $100 \mu \mathrm{L}$ LM. ${ }^{\mathrm{d} 3} \mathrm{p}<0.001$ significantly different compared with platelets treated with $200 \mu \mathrm{L}$ LM. ${ }^{\mathrm{e} 2} \mathrm{p}<0.01$ significantly different compared with platelets treated with $500 \mu \mathrm{L} \mathrm{LM} .{ }^{\mathrm{e} 3} \mathrm{p}<0.001$ significantly different compared with platelets treated with $500 \mu \mathrm{L}$ LM.

Platelets play a vital role in hemostasis by interacting with activated plasma clotting factors at the site blood vessel injury and form a hemostatic plug (Harker and Mann, 1992). Platelet aggregation is the process of adhesion of platelets to each other at the site of blood vessel injury and cause thrombosis. Platelet aggregation is induced by number of agonists such as Adenosine diphosphate (ADP), Collagen, Thrombin, etc (Rumbaut and Thiagarajan, 2010). LMWH have lower reactivity to platelets but have anticoagulant activity in normal platelets rich plasma. It protects the platelets from aggregation by the formation of heparin-AT complex (Mousa, 2004). In this study, the antiplatelet aggregation of LM and LMWH was evaluated against thrombin and ADP induced platelet aggregation in blood samples of rat. The inhibitory activity of LM at different concentrations was tested on thrombin and ADP induced platelet aggregation. The results are presented in the figure $3,4 \& 5$ as percentage of aggregation formation/inhibition \pm S.E.M. Distilled water treated blood samples did not show any activity against thrombin and ADP activity. Heparin had the highest inhibitory activity on compared with other test groups. LM exhibited a dose dependent inhibitory activity on platelet aggregation induced by Thrombin and ADP. Among the different concentrations of $\mathrm{LM}, 1000 \mu \mathrm{L}$ exhibited more efficacious inhibitory activity $(\mathrm{P}<0.001)$ of platelet aggregation and closely comparable with that of LMWH.

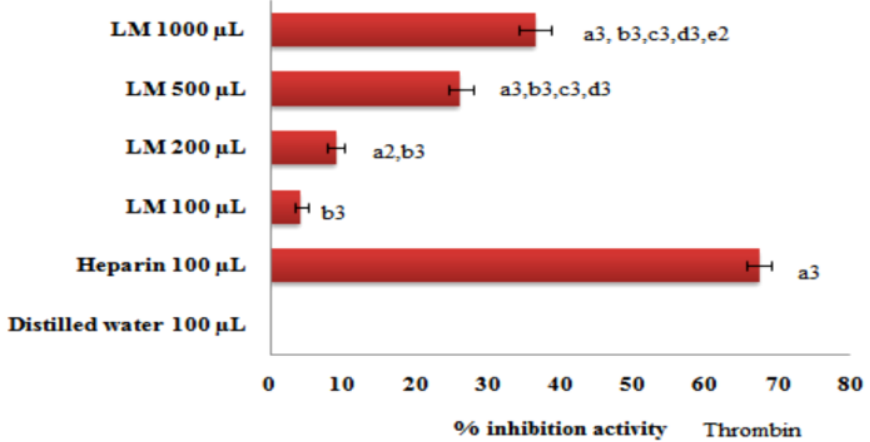

Fig. 4: Effect of the different concentrations of Linga Mathirai (LM) on percentage of inhibition of aggregation on rat platelets induced by Thrombin compared to normal saline and low molecular weight heparin. Data are expressed as mean \pm SEM, where $\mathrm{n}=4$; One way ANOVA: Tukey's multiple comparision test. ${ }^{\mathrm{a} 3} \mathrm{p}<0.001$ significantly different compared with platelets treated with distilled water. ${ }^{a 2} \mathrm{p}<0.01$ significantly different compared with platelets treated with distilled water. ${ }^{b 3} p<0.001$ significantly different compared with platelets treated with heparin. ${ }^{c 3} p<0.001$ significantly different compared with platelets treated with $100 \mu \mathrm{L}$ LM. ${ }^{\mathrm{d} 3} \mathrm{p}<0.001$ significantly different compared with platelets treated with $200 \mu \mathrm{L}$ LM. ${ }^{\mathrm{e} 2} \mathrm{p}<0.01$ significantly different compared with platelets treated with $500 \mu \mathrm{L} \mathrm{LM}$.

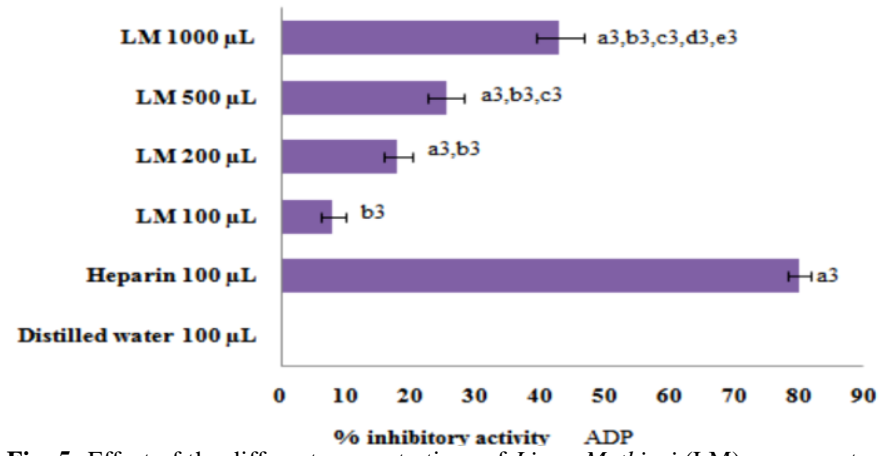

Fig. 5: Effect of the different concentrations of Linga Mathirai (LM) on percentage of inhibition of aggregation on rat platelets induced by Adenosine diphosphate (ADP) compared to normal saline and low molecular weight heparin. Data are expressed as mean \pm SEM, where $n=4$; One way ANOVA: Tukey's multiple comparision test. ${ }^{\mathrm{a} 3} \mathrm{p}<0.001$ significantly different compared with platelets treated with distilled water. ${ }^{b 3} \mathrm{p}<0.001$ significantly different compared with platelets treated with heparin. ${ }^{\mathrm{c} 3} \mathrm{p}<0.001$ significantly different compared with platelets treated with $100 \mu \mathrm{L}$ LM. ${ }^{\mathrm{d} 3} \mathrm{p}<0.001$ significantly different compared with platelets treated with $200 \mu \mathrm{L} \mathrm{LM} .{ }^{\mathrm{e} 3} \mathrm{p}<0.001$ significantly different compared with platelets treated with $500 \mu \mathrm{L} \mathrm{LM}$ 


\section{CONCLUSION}

From the results acquired from the above studies, LM demonstrated no statistically significant clot lytic property in different rat blood samples but the clot lysis activity is comparable with LMWH and also the study revealed that LM have marked antiplatelet aggregation property. It can be concluded that Linga Mathirai show better anticoagulant activity comparable to low molecular weight heparin and further in vivo studies have to be conducted on Linga Mathirai.

\section{ACKNOWLEDGEMENT}

The authors wish to thank Vice Chancellor and Department of Siddha, The Tamil Nadu Dr. MGR Medical University, Chennai and the management of Sairam Group of Institutions for their support.

\section{REFERENCES}

Abdhula Sayubu PM. 1995. Anubhoga Vaidhya Navaneetham, IV Part. Chennai: Thamarai Noolagam.

Badimon L, Padro T, Vilahur G. Atherosclerosis, platelets and thrombosis in acute ischaemic heart disease. European Heart Journal: Acute Cardiovascular Care, 2012; 1(1):60-74.

Born G, Cross M. The aggregation of blood platelets. J Physiol, 1963; 168:178-195.

Chamuleau SA, Winter RJ de, Levi M, Adams R, Büller HR, Prins MH, Lie KI, Peters RJG. Low molecular weight heparin as an adjunct to thrombolysis for acute myocardial infarction: the FATIMA study. Heart, 1998; 80:35-39.

Ernest Palomeras Soler, Virgina Casado Ruiz. Epidemiology and Risk Factors of Cerebral Ischemia and Ischemic Heart Diseases: Similarities and Differences. Current Cardiology Reviews, 2010; 6:138149.

Fry ETA, Sobel BE. Lack of interference by heparin with thrombolysis or binding of tissue-type plasminogen activator to thrombi. Blood, 1988; 71(5):1347-1352.

Harker LA, Mann KG. 1992. Thrombosis and fibrinolysis. In: Fuster V, Verstraete M, ed. Thrombosis in Cardiovascular Disorders. Philadephia: WB Saunders 1-16.

Henry BL, Thakkar JN, Martin EJ, Brophy DF, Desai UR. Characterization of the plasma and blood anticoagulant potential of structurally and mechanistically novel oligomers of 4 hydroxycinnamic acids. Blood Coagul Fibrinolysis, 2009; 20:27-34.

Janet Fitzakerley. 2006. Hematopoiesis and Host Defences. [ONLINE] Available at: http://www.d.umn.edu/ jfitzake /Lectures/MedSchool/ Downloads/2006Anticoagulants.pdf
Jayaprakash Narayanan P, Ganapathy G, Natarjan K, Krishnamurthi JR, Subramanian V, Rajeswari K, Nataraja Chokkalingam, Padmapriya M, Thenmozhi P. 2011. Siddha Medicine, Volume II, Fundamentals. Chennai: Tamil Valarchi Kazhagam.

Kojima S, Soga W, Hagiwara H, Shimonaka M, Saito Y, Inada Y. Visible fibrinolysis by endothelial cells: Effect of vitamins and sterols. Biosci Rep, 1986; 6:1029-1033.

Kuppusamy Mudhaliar KN. 2004. Siddha Maruthuvam Pothu. Chennai: Department of Indian Medicine and Homeopathy.

Matsuura H. Saponins in garlic as modifiers of the risk of cardiovascular disease. J Nutr, 2001; 131:1000S-1005S.

Mousa Shaker A. 2004. Heparin and LMWH in thrombosis. In: Mousa Shaker A, ed. Anticoagulants, Antiplatelets and Thrombolytics. New Jersey: Humana Press Inc 38.

Prasad Sweta, Kashyap Rajpal S, Deopujari Jayant Y, Purohit Hemant J, Taori Girdhar M, Daginawala Hatim F. 2006. Development of an invitro model to study clot lysis activity of thrombolytic drugs. [ONLINE] Available at http://thrombosisjournal.biomedcentral.com/articles/10.1186/1477-95604-14. [Accessed 12 September 2006]

Pietri S, Maurelli E, Drieu K, CulcasiM. Cardioprotective and anti-oxidant effects of the terpenoid constituents of Ginkgo biloba extract (EGb 761). J Mol Cell Cardiol, 1997; 29:733-742.

Rumbaut RE, Thiagarajan P. 2010. Platelet-Vessel Wall Interactions in Hemostasis and Thrombosis. San Rafael, California: Morgan \& Claypool Life Sciences Publisher.

Thiyagarajan, R. 2008. Pancha sootham. In: Anaivari Anandan R, Thulasimani M, ed. Siddha Materia Medica Mineral \& Animal section. Chennai: Department of Indian Medicine and Homoeopathy 222.

Umesh MK, Sanjeevkumar CB, Hanumantappa Bherigi Nayaka, Ramesh L Londonkar. Evaluation of in vitro anti-thrombolytic activity and cytotoxicity potential of Typha angustifolia L leaves extracts. Int J Pharm Pharm Sci, 2014; 6(5):81-85.

Vermylen J, Verstraete M, Fuster V. Role of Platelet Activation and Fibrin Formation in Thrombogenesis. J Am Coll Cardiol, 1986; 8:2B9B.

Wiegand Gesa, Icheva Vanya, Martin Schöning, Michael Hofbeck. Successful thrombolysis following enoxaparin therapy in two pediatric patients with congenital heart disease presenting with intracardiac and cerebral thrombosis. Thrombosis Journal, 2014; 12:19.

\section{How to cite this article:}

Vembu T, Sivagnanam M, Murugan PK. In vitro Anticoagulant Activity of Siddha Sastric Formulation Linga Mathirai compared with Low Molecular Weight Heparin. J App Pharm Sci, 2016; 6 (06): 061-065. 